\title{
Eight new species of Ptenidiini and Discheramocephalini (Coleoptera: Ptiliidae) from Ecuador
}

\author{
Michael DARBY \\ Department of Life Sciences, Natural History Museum, London, SW7 5BD UK. \\ E-mail: m.darby@nhm.ac.uk \\ urn:lsid:zoobank.org:author:FA87E30B-5023-4169-A47C-EB1EBC0A7EA1
}

\begin{abstract}
Eight new species of Ecuadorian Ptiliidae are described and figured: Nossidium harrietae sp. nov., Ptenidium robustum sp. nov., $P$. tauriforme sp. nov., $P$. triangulum sp. nov., Notoptenidium brunneum sp. nov., Americoptilium nigrescens sp. nov., Discheramocephalus nigerrimus sp. nov. and D. striatus sp. nov. The insects were collected by J. McClarin, 2017-2018, in the Napo Province to the southeast of the capital Quito.
\end{abstract}

Keywords. Coleoptera, Ptiliidae, Ecuador, new species.

Darby M. 2020. Eight new species of Ptenidiini and Discheramocephalini (Coleoptera: Ptiliidae) from Ecuador. European Journal of Taxonomy 599:1-19. https://doi.org/10.5852/ejt.2020.599

\section{Introduction}

Blackwelder (1944-57) listed no Ptiliidae from Ecuador, and although Johnson has recorded nine species from the Galapagos Islands since (Johnson 1982b), no named species had been recorded from the mainland until the first paper in this series (Darby 2018b). Ptiliidae have been recorded from adjoining Peru (Darby \& Chaboo 2015a, 2015b; Darby 2016a, 2016b, 2016c). This paper continues that research and is based on new collections of 680 Ptiliidae made by Jim McClarin, Field Collaborator, Museum of the Pontifical Catholic University of Ecuador, Quito, Ecuador (QCAZM). The insects were collected between 2017 and 2018 at his forest camp in Cosanga, Napo Province, to the southeast of the capital Quito (for Map showing location of site see Darby 2018b). The permit for collecting included deposition of the holotypes in QCAZM, with a selection of paratypes to the Natural History Museum, London (BMNH).

\section{Material and methods}

After preliminary sorting the insects were transferred into a series of microtubes filled with rolls of paper soaked in alcohol (as required to conform with local legislation concerning the shipping of flammable liquids) before being passed to the writer. Further research was then carried out using a Leica M165C stereo microscope, an Olympus BH2 compound microscope fitted with differential contrast, and a Phenom scanning electron microscope. Images and measurements were made using the built-in software and cameras of the Phenom, a Leica DFC450 digital camera and associated software attached to the stereo microscope, and a Canon EOS 1100D digital camera with associated software attached to 
the Olympus microscope. The images were prepared for publication using Helicon stacking software and Corel PaintShop Pro software, care being taken not to alter or obscure any features. All specimens selected for detailed study were subsequently mounted on cards with dissections mounted in Euparal on an acrylic sheet pinned with the dry mounted specimens and labels.

The references to 'droplet' is a method of collecting described by McClarin (in lit.) as one he "accidentally discovered for trapping beetles and little else. Water from rain or other sources beads up on new polyethylene sheeting and the droplets suck in small beetles and keep them trapped via surface tension." Illustrations of the process are available at https://www.flickr.com/photos/36494393@N00/albums/72157683620944426. Collections described as 'tray' were made from a white photographic tray placed on the collector's table.

The length measurement is taken from the front of the head to the apex of the elytra. Habitus and genitalia measurements were made using the camera and built-in software attached to the Leica microscope and measurements of the antennae and metaventrite made using the inbuilt software of the SEM. Magnifications are those of the original SEM pictures. The use of the term 'mid-keel' to distinguish the area between the mesoventrite collar and its median extension and the part of the mesoventrite keel falling between the mesocoxae follows Darby (in press).

\title{
Institutional abbreviations
}

$\mathrm{BMNH}=$ British Museum of Natural History, London, United Kingdom

QCAZM = Museum of the Pontifical Catholic University of Ecuador, Quito, Ecuador

\section{Results}

\author{
Order Coleoptera Linnaeus, 1758 \\ Family Ptiliidae Erichson, 1845 \\ Subfamily Ptiliinae Erichson, 1845 \\ Tribe Ptenidiini Flach, 1889
}

Genus Nossidium Erichson 1845

\section{Type species}

Dermestes pilosellus Marsham, 1802.

\section{Diagnosis}

Distinctive genus of Ptiliidae which agrees with Sindosium Johnson, 2007 (two species from the Solomon Islands and one from Sabah), Motschulskium Matthews, 1872 (one species from California) and Bicavella Johnson, 2007 (two species from the Solomon Islands) in having membranous wings without a clear medial constriction and aedeagi with parameres, but is separated from them by their more globular form and the absence of a clear waist at the junction of the elytra and pronotum. Three species of Nossidium have been described from Central and South America: N. issyae Darby, 2016 and N. schuelkei Darby, 2016 from Costa Rica and N. katyae Darby, 2015 from Bolivia. They differ from the two north American species I have studied, N. americanum, Motschulsky, 1868 and N. amoenum Motschulsky, 1868, and from the two Palaearctic species N. pilosellum Marsham, 1802 and N. flachi Ganglbauer, 1898, in being much rounder and less parallel-sided. No external features have been noted to distinguish males and females. 
Nossidium harrietae sp. nov.

urn:lsid:zoobank.org:act:808DC202-D54F-4596-A8C4-974DB2200DF5

Fig. $1 \mathrm{~A}-\mathrm{G}$

\section{Etymology}

Named after Harriet Oram, a close friend of the author's family.

\section{Material examined}

Holotype

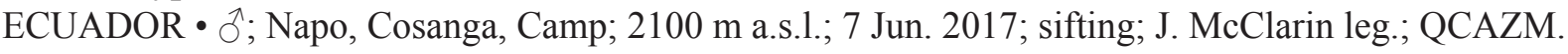

\section{Paratypes}

ECUADOR -6 spec.; same data as for holotype; one mounted ventral side uppermost; BMNH, QCAZM - 3 spec.; same data as for holotype but 8 Jun. 2017; BMNH, QCAZM -2 spec.; same data as for holotype but 6 Jun 2017; QCAZM • 1 spec.; same data as for holotype but 11 Jun. 2017; abdomen only; mounted as a slide; BMNH • 35 spec.; Napo, Cosanga, Camp, flotsam; 2100 m a.s.1.; 1 Jul. 2017; in alcohol; BMNH.

\section{Description}

Size. Habitus length $0.89 \mathrm{~mm}$, globose species, (Fig. 1A).

CoLour. Dark brown, shining; pubescence, antennae and legs dusky yellow.

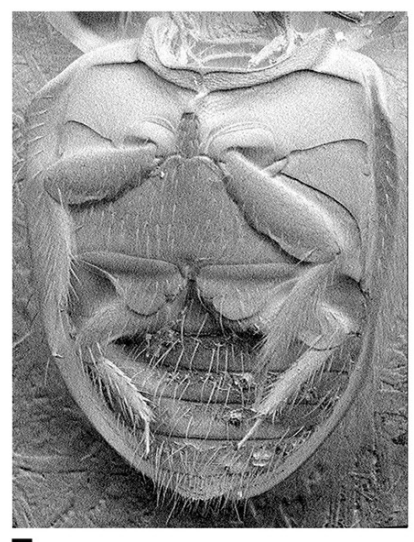

F

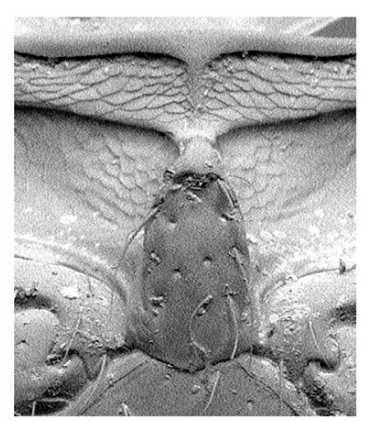

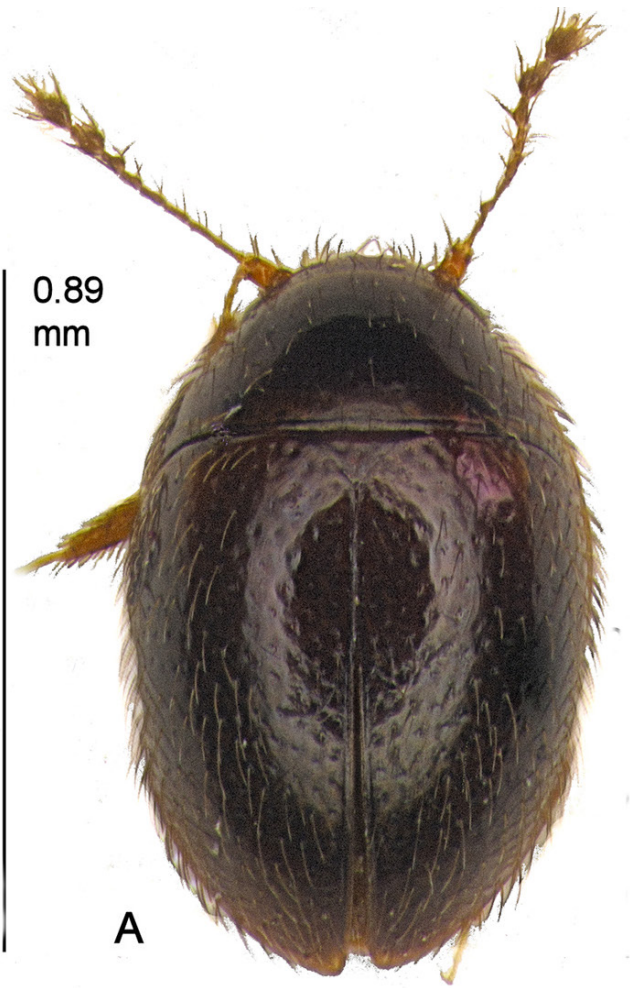

$\mathrm{E}$
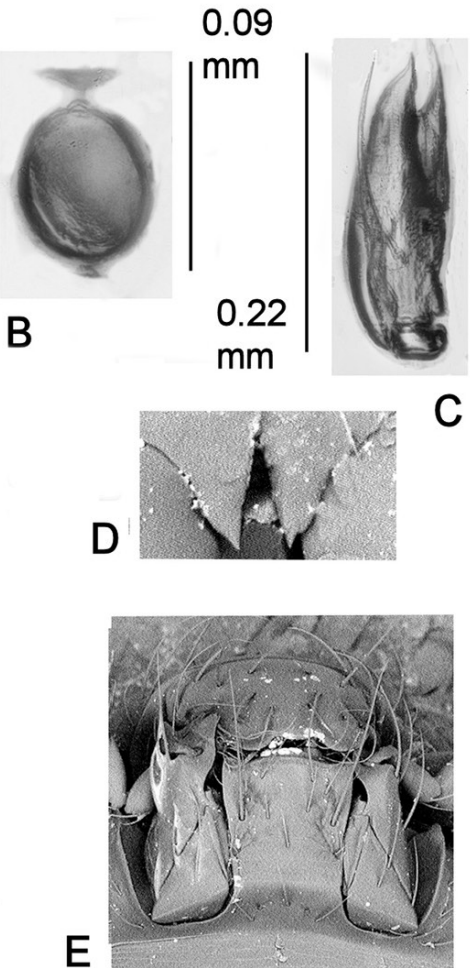

Fig. 1. Nossidium harrietae sp. nov. A. Habitus. B. Spermatheca. C. Aedeagus. D. Bifurcate projection of the metaventrite between the metacoxae $\times 1480$. E. Mentum and prementum $\times 900$. F. Venter $\times 288$. G. Mesoventrite keel $\times 855$. 
HEAD. Smooth, shining, with sparse pubescence, width across eyes $0.32 \mathrm{~mm}$; antennomeres III-XI length $0.38 \mathrm{~mm}$, the two basal segments forming a scape and IX-XI a loosely jointed club; mentum tapering posteriorly, with two long setae situated medially on lateral margins, anterior margin concave before sinuate corners, prementum with 5-6 setae (Fig. 1E); labrum setose.

Pronotum. Length $0.20 \mathrm{~mm}$, width $0.58 \mathrm{~mm}$, widest basally, disc simple, pubescence confined to sides, hind corners posteriorly directed in dorsal view, lateral margins with narrow borders in lateral view.

ELYTRA. Length $0.67 \mathrm{~mm}$, width $0.60 \mathrm{~mm}$, widest at humeri, completely covering abdomen, shallowly foveolate, pubescent setae of same length as those on pronotum, with wide pubescent epipleura.

ScutelLum. Small, triangular.

Prosternum. Very narrow in front of procoxae, which are adjacent and with short keel anteriorly reaching midpoint of coxal cavities; coxal cavities open behind.

MesoventRIte. Collar reticulate, narrow, with sharply defined anterior margin produced medially as a narrow extension to posterior margin, extended onto humeri without forming a humeral tooth; mesocoxae separated by a broad, flattened, reticulate, pubescent keel, which slopes sharply anteriorly as narrow ridge to posterior margin of collar (Fig. 1G), posterior margin sinuate before meeting lateral margin (Fig. 1F).

MetaVentRite. Length $0.18 \mathrm{~mm}$, width $0.49 \mathrm{~mm}$, with sparse pubescence, anterior margin with broad raised border around mesocoxae, metepisternal sutures clearly marked, turning sharply posteriad before lateral margin, metacoxae separated by a bifurcate extension of metaventrite, which is not sharply pointed (Fig. 1D), coxal plates rounded before tapering to a point at lateral margin (Fig. 1F).

WINGS. Without clear medial restriction, fringed with setae.

MALE Genitalia. Aedeagus with narrow parameres (Fig. 1C).

Female genitalia. Spermatheca rounded (Fig. 1B).

\section{Remarks}

Nossidium harrietae sp. nov. shares with N. katyae Darby, 2015 and N. schuelkei Darby, 2016 a wide and flattened mesoventrite keel separating the mesocoxae, but is distinguished from the former by its more globular rounded form, disc of pronotum without pubescence and the sharp spines on the bifurcate metaventrite process, and from the latter by the much less densely punctured and pubescent dorsum.

Genus Ptenidium Erichson, 1845

\section{Type species}

Scaphidium pusillum Gyllenhal, 1808.

\section{Remarks}

Ptenidium is a well-defined genus of distinctive beetles distributed throughout the world, although most species have been described from the northern hemisphere, with the concentration being in the Palaearctic region. The establishment of a group of Neotropical species with distinctive pronotal and spermathecal characteristics was made by Darby (2016c), who placed them in a separate subgenus, Peruvium. It is to this subgenus that the three new species described below belong. 
Ptenidium (Peruvium) robustum sp. nov.

urn:1sid:zoobank.org:act:74D1C558-2EF0-4AF3-A998-F7E7053CAD23

Fig. 2A-E

\section{Etymology}

Named after the robust appearance of the species.

\section{Material examined}

\section{Holotype}

ECUADOR • 今'; Napo, Cosanga; 2100 m a.s.1.; 7 May 2017; droplet; J. McClarin leg.; QCAZM.

\section{Paratype}

ECUADOR • 1 $\widehat{\jmath}$, no data [presumed to be Napo, Cosanga]; J. McClarin leg.; BMNH.

\section{Description}

Size. Habitus length $0.95 \mathrm{~mm}$ (Fig. 2A).

CoLour. Dark brown/black, shining appearing polished, glabrous, legs dark red/brown, antennae yellow, club markedly darker.

HEAD. Smooth, shining, with a small tuft of setae on disc (Fig. 2E), width across eyes $0.33 \mathrm{~mm}$; antennomeres III-XI length $0.26 \mathrm{~mm}$, the two basal segments forming a scape and IX-XI a loosely

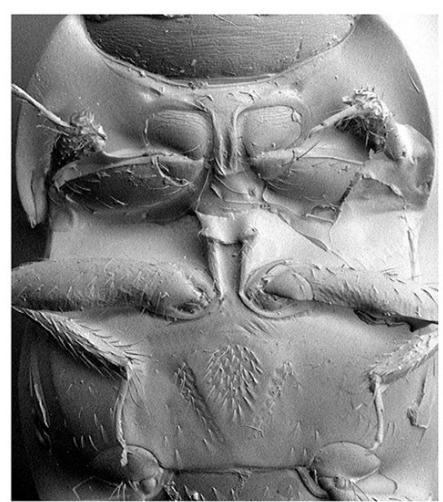

D

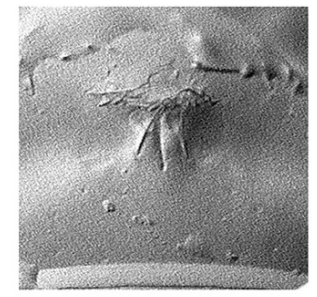

$\mathrm{E}$

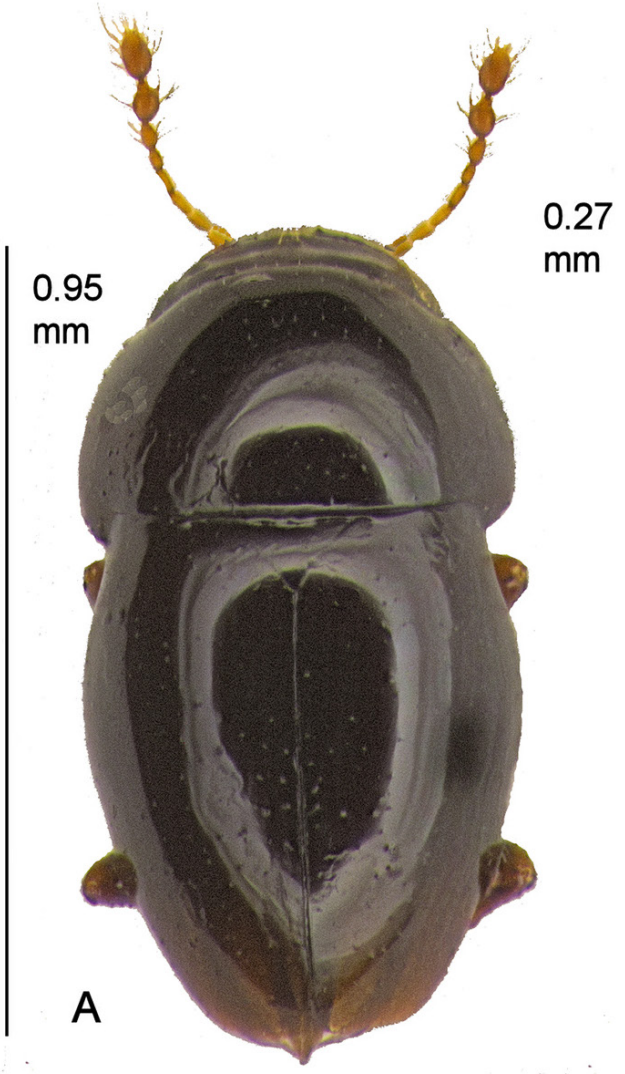

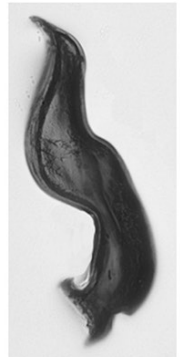

$\mathrm{Ba}$

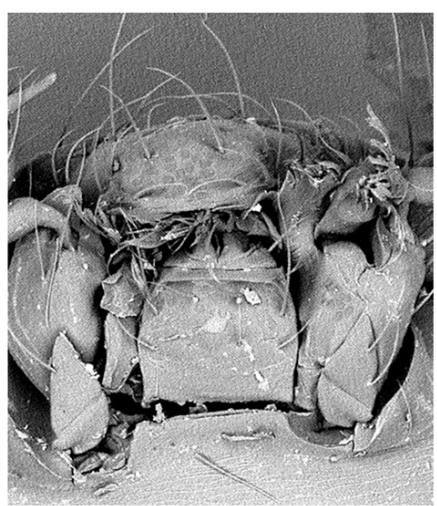

C

Fig. 2. Ptenidium robustum sp. nov. A. Habitus. B. Lateral (Ba) and dorsal (Bb) views of the aedeagus. C. Mentum and prementum $\times 725$. D. Venter $\times 400$. E. Tuft of setae on the head $\times 520$. 
jointed club; mentum chaetotaxy of usual Ptenidium type, sides rounded and narrower anteriorly, prementum with 5-6 setae; labrum setose with shallow circular depressions.

Pronotum. Length $0.31 \mathrm{~mm}$, width $0.52 \mathrm{~mm}$, broad, widest before rounded hind angles, without setae in lateral margins and foveae on anterior and posterior margins, traces of setae only on posterior margin at angles.

ELYTRA. Length $0.61 \mathrm{~mm}$, width $0.52 \mathrm{~mm}$, widest just anterior to middle, leaving only tip of abdomen exposed.

Scutellum. Small, triangular, without basal depressions/foveae.

PRosternum. Very narrow in front of procoxae, which are separated by parallel-sided keel with distinct longitudinal depression (Fig. 2D).

Mesoventrite. Glabrous, without reticulation; mid keel with depressed medial channel; keel side margins extending posteriorly as carinae meeting side borders of mesocoxal cavities, median area depressed, forming a longitudinal channel; mesoventrite posterior margin almost straight to lateral margins (Fig. 2D).

MetaVentrite. Length $0.20 \mathrm{~mm}$, width $0.46 \mathrm{~mm}$, disc with a triangular patch of short setae, anterior margin with raised border before posterior margin of mesocoxal cavities, metepisternal sutures not visible, posterior margin between metacoxae straight, length $0.17 \mathrm{~mm}$, coxae without coxal plates.

Wings. Of usual ptiliid type.

Male Genitalia. Aedeagus (Fig. 2Ba-Bb).

Female genitalia. Not known.

\section{Remarks}

This species is only likely to be confused with P. gibbosum Darby, 2016 from Bolivia amongst the subgenus Peruvium species which also have a longitudinal depression down the proventral intercoxal keel and the males of which have a small tuft of setae on the head (Darby 2016c), but the broad pronotum, shape of the aedeagus and absence of protuberances on the head quickly distinguish it.

Ptenidium (Peruvium) tauriforme sp. nov.

urn:1sid:zoobank.org:act:E697F71F-1EC8-48DD-BD38-C96C486EB8A7

Fig. $3 \mathrm{~A}-\mathrm{G}$

\section{Etymology}

After the Latin adjective tauriformis, meaning bull-like and referring to the tuberosities on the head.

\section{Material examined}

\section{Holotype}

ECUADOR • つ’; Napo, Cosanga, Camp; 2100 m a.s.1.; 9 Jul. 2017; droplet; J. McClarin leg.; QCAZM.

\section{Description}

Size. Habitus length $1.25 \mathrm{~mm}$ (Fig. 3A). 
CoLour. Dark brown/black, shining, appearing polished, glabrous, legs and antennae dusky yellow/ brown.

HEAD. Setose, with two rounded tuberosities at base and short median raised ridge anterior to these (Fig. 3G), width across eyes $0.37 \mathrm{~mm}$; antennomeres III-XI length $0.29 \mathrm{~mm}$; mentum chaetotaxy unclear, sides rounded to anterior margin, prementum with 5-6 setae.

Pronotum. Length $0.38 \mathrm{~mm}$, width $0.56 \mathrm{~mm}$, sides evenly rounded, with tufts of hairs on corners of posterior margin (Fig. 3C), and without lateral setae and foveae on anterior and posterior margins.

ELYTRA. Length $0.80 \mathrm{~mm}$, width $0.59 \mathrm{~mm}$, widest just anterior to middle, tapering posteriad.

Scutellum. Small, triangular, with short medial keel on anterior margin.

Prosternum. Very narrow in front of procoxae, which are separated by long, narrow, parallel-sided keel (Fig. 3E).

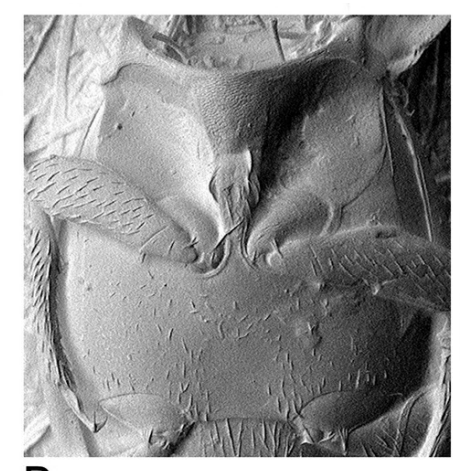

D
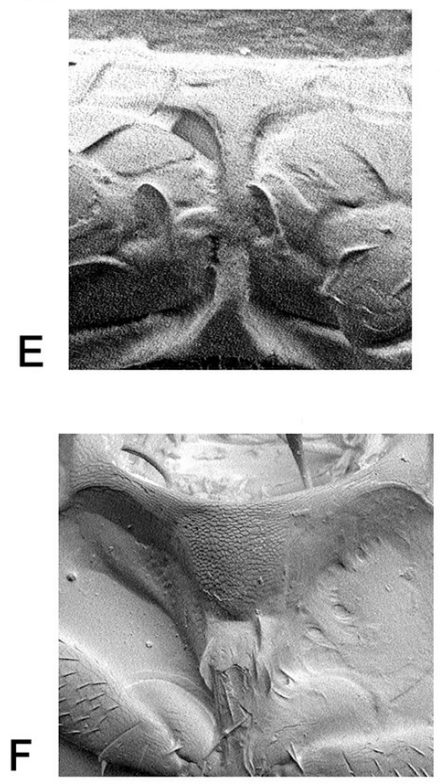

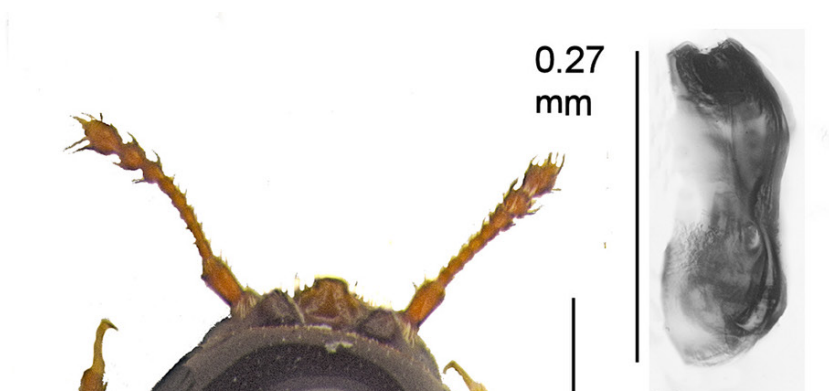

$\mathrm{Ba}$

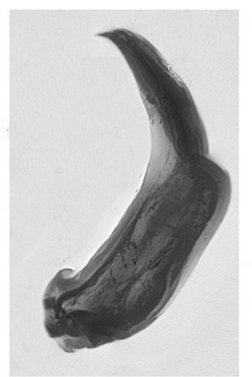

$\mathrm{Bb}$

C

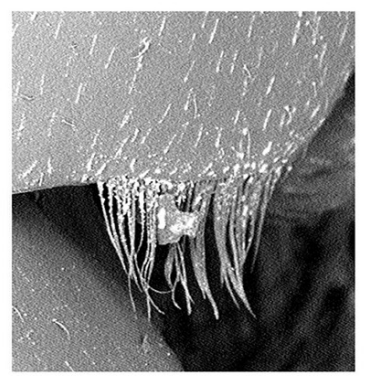

A

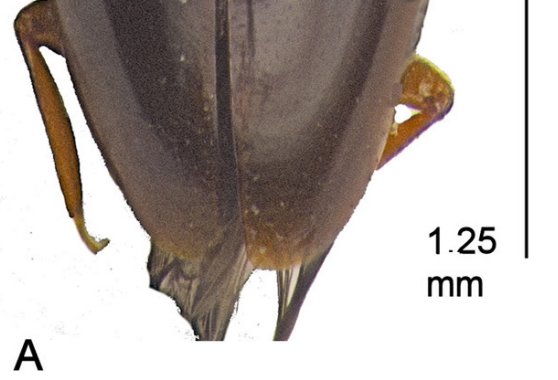

G

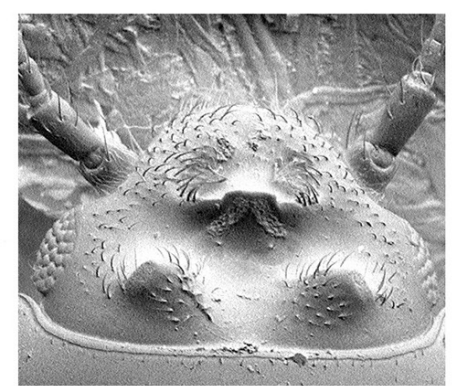

Fig. 3. Ptenidium tauriforme sp. nov. A. Habitus. B. Dorsal (Ba) and lateral (Bb) views of the aedeagus. C. Tuft of setae at the posterior angle of the pronotum $\times 835$. D. Venter $\times 260$. E. Prosternum showing keel between the procoxae $\times 810$. F. Mesoventrite collar and keel $\times 455$. G. Head showing tuberosities $\times 460$. 
Mesoventrite. Collar reticulate, with wide, shallowly tapering medial extension to mid-keel and keel, which are setose and rather flatter than in usual Ptenidium type (Fig. 3F), posterior margin turned sharply posteriad at humeri; mesoventrite posterior margin evenly rounded to small tooth at humeri.

MetaVentrite. Length $0.22 \mathrm{~mm}$, width $0.50 \mathrm{~mm}$, disc simple, with scattered pubescence, metepisternal sutures not visible, posterior margin between metacoxae straight, length $0.13 \mathrm{~mm}$, coxae without coxal plates.

WINGS. Of usual ptiliid type.

Male genitalia. Aedeagus (Figs 3Ba-Bb).

Female genitalia. Not known.

\section{Remarks}

The naming of this species on the basis of a single specimen is justified by the distinctive sculpture of the head and particularly by the form of the mesoventrite collar, both of which are unlike in any other Ptenidium spp. described to date.

Ptenidium (Peruvium) triangulum sp. nov. urn:1sid:zoobank.org:act:D49B2C8D-87D8-4E05-84A2-F2EB3F324A2C

Fig. 4A-E

\section{Etymology}

Named after the shape of the proventral intercoxal process.

\section{Material examined}

\section{Holotype}

ECUADOR • ${ }^{\lambda}$; Napo, Cosanga, Camp D Mel; 2100 m a.s.1.; 3 Mar. 2018; dead leaves from crown of felled tree in family Melastomataceae; J. McClarin leg.; QCAZM.

\section{Description}

Size. Habitus length $0.97 \mathrm{~mm}$ (Fig. 4A).

CoLour. Dark brown/black, dorsum finely punctured throughout with very short pubescence, legs and antennae yellow/brown.

HEAD. With shallow point medially on disc near anterior margin, width across eyes $0.28 \mathrm{~mm}$; antennomeres III-XI length $0.31 \mathrm{~mm}$; mentum chaetotaxy of usual Ptenidium type, sides strongly rounded to anterior margin, prementum with 5-6 setae.

Pronotum. Length $0.27 \mathrm{~mm}$, width $0.44 \mathrm{~mm}$, broad, widest before strongly rounded hind angles, without setae in lateral margins and foveae on anterior and posterior margins, posterior margin strongly sinuate at lateral angles, with tufts of setae (Fig. 4C).

ELYTRA. Length $0.55 \mathrm{~mm}$, width $0.47 \mathrm{~mm}$, shallowly rounded, widest just anterior to middle.

Scutellum. Small, triangular, with very small median keel on anterior margin.

Prosternum. Very narrow in front of procoxae, which are separated by an elongate, triangularly shaped keel (Fig. 4E). 
Mesoventrite. Reticulate, collar extending narrowly onto humeri, forming blunt teeth, medially with three extensions onto mid-keel, which is setose at margins; keel of usual Ptenidium type, with two long setae at base and setose lateral arms extending posteriad to join margins of mesocoxal cavities, mesocoxae not adjacent; mesoventrite posterior margin shallowly curved to lateral margins (Fig. 4D-E).

MetaVentrite. Length $0.19 \mathrm{~mm}$, width $0.46 \mathrm{~mm}$, sparsely pubescent but thickened medially at rear margin, distance between metacoxae $0.13 \mathrm{~mm}$, mesocoxal cavities narrowly bordered, metepisternal sutures not visible.

Male genitalia. Aedeagus (Fig. 4Ba-Bb).

Female genitalia. Not known.

\section{Remarks}

Description on the basis of a single specimen is considered justified by the triangular shape of the procoxal process, which is different from that in all other species in the subgenus Peruvium described to date.

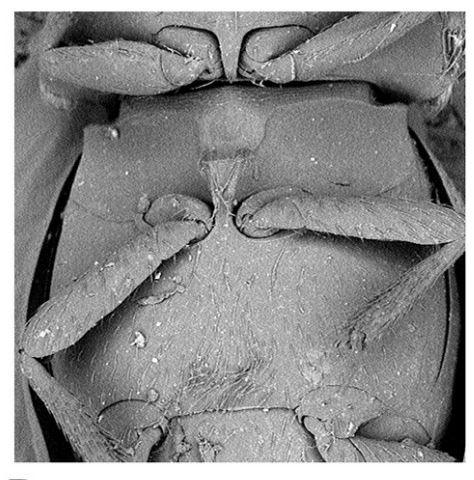

D

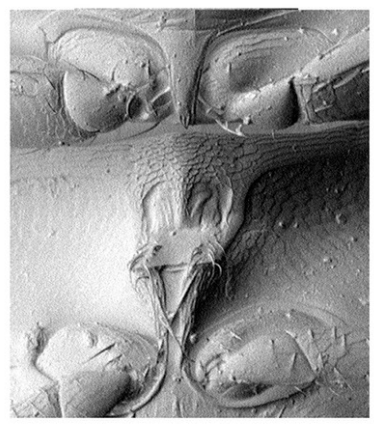

$\mathrm{E}$

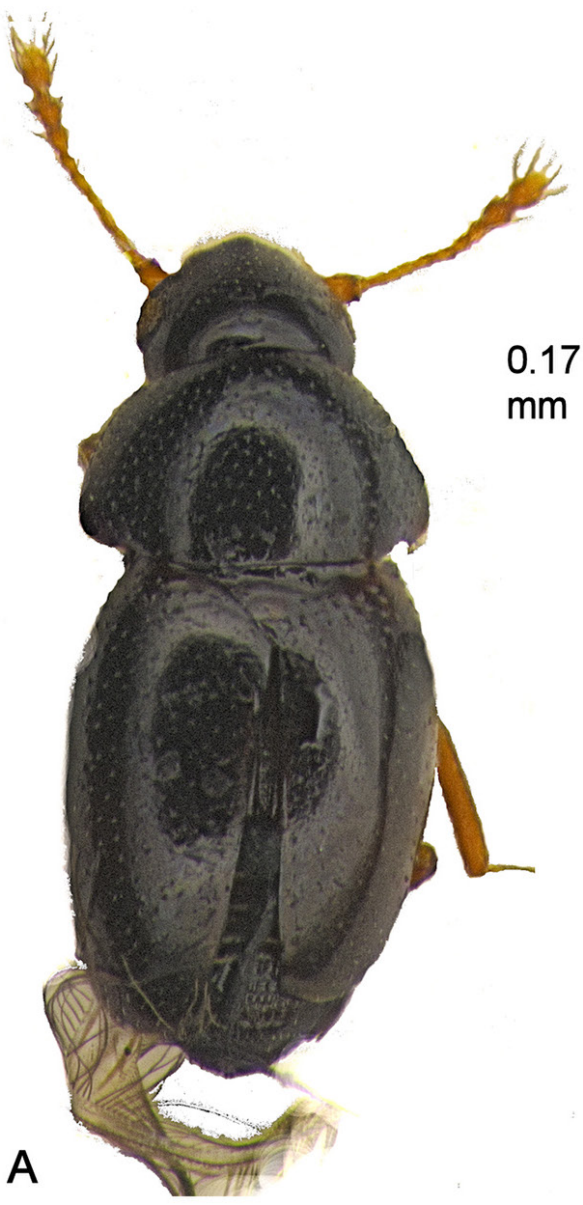

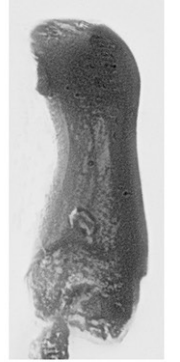

$\mathrm{Ba}$

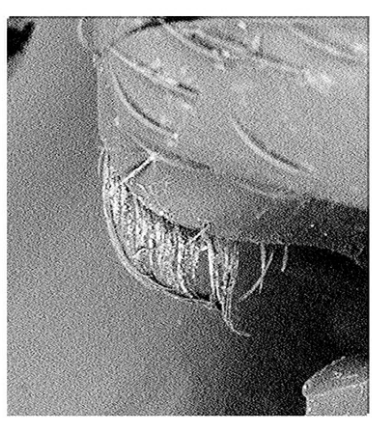

C

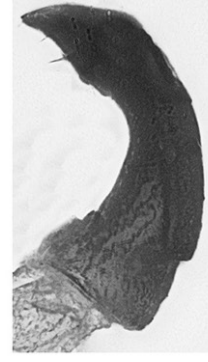

$\mathrm{Bb}$

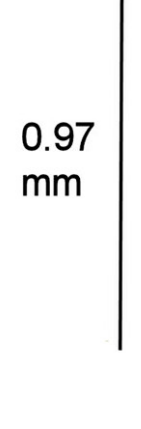

A

Fig. 4. Ptenidium triangulum sp. nov. A. Habitus. B. Dorsal (Ba) and lateral (Bb) views of aedeagus. C. Tuft of setae at the posterior angle of the pronotum $\times 1200$. D. Venter $\times 335$. E. Pro- and mesoventra, showing keels between the pro- and mesocoxae $\times 675$. 
Genus Notoptenidium Johnson, 1982

\section{Type species}

Ptenidium lawsoni Matthews, 1873.

\section{Remarks}

Notoptenidium ('southern Ptenidium') was described by Johnson (1982a) on the basis of nine species from New Zealand and has not been recorded from any other country since, although he did note having seen an undescribed species from Australia. Two further species from New Zealand were added by Darby (2018a).

Notoptenidium brunneum sp. nov. urn:1sid:zoobank.org:act:5E931BD0-8D23-489B-8F74-6FE90ED77F0C

Fig. $5 \mathrm{~A}-\mathrm{G}$

\section{Etymology}

Named after the dark brown colour of the species.

\section{Material examined}

\section{Holotype}

ECUADOR • o; Napo, Cosanga, Camp BOO; 2100 m a.s.1.; 22 Feb. 2016; ex bamboo; J. McClarin leg.; QCAZM.

\section{Description}

Size. Habitus length $0.91 \mathrm{~mm}$ (Fig. 5A).

CoLour. Head and pronotum almost black, elytra dark brown, legs and antennae dusky yellow.

HEAD. Sparsely pubescent, width across eyes $0.25 \mathrm{~mm}$; antennomeres III-XI length $0.27 \mathrm{~mm}$; mentum almost square, sides slightly convex, prementum with five setae, two being much longer than the others (Fig. 5D).

Pronotum. Length $0.23 \mathrm{~mm}$, width $0.34 \mathrm{~mm}$, punctured and pubescent, narrowly bordered, lateral margins slightly sinuous before obtuse hind angles, anterior angles visible in dorsal view.

Scutellum. With wide base and two small depressions medially.

ELYTRA. Length $0.56 \mathrm{~mm}$, width $0.42 \mathrm{~mm}$, with overlapping pubescence, lateral margins evenly rounded and narrowly bordered in basal half.

Prosternum. Bordered anteriorly, sparsely pubescent medially and with a series of shallow pits anterior to procoxae, which are contiguous, without keel.

MESOVEnTRITE. With strongly reticulate, elaborately sculpted collar and mid-keel unique to this genus; collar extending narrowly onto humeri, with distinct tooth; posterior margins shallowly serrate and sloping strongly anteriorly to lateral margins; mesocoxae not contiguous, separated by keel, which is pubescent (Fig. 5E).

METAVENTRITE. Without reticulation, sparsely pubescent, posterior margin between metacoxae convex, without lateral spines, posterior margins of mesocoxae without serrations.

Wings. Macropterous. 
Male genitalia. Aedeagus not known.

Female genitalia. Spermatheca (Fig. 5C).

\section{Remarks}

The genus is immediately distinguishable from all other Ptiliidae by the form of the mesoventrite collar and keel. N. brunneum sp. nov. is only likely to be confused with three of the New Zealand species: N. kuscheli Johnson, 1982, from which it may be separated by the presence of punctures on the pronotum; N. similatum Johnson, 1982, which has a larger and simpler spermatheca with fewer coils; and $N$. lawsoni (Matthews, 1873), the commonest of the New Zealand species, by its narrower and less rounded pronotum, the lack of punctures on the metaventrite and its proportionately longer elytra.

The wide geographical separation of the Ecuadorian and New Zealand species is difficult to account for, but is most likely explained as the result of a sea-borne passage across the Pacific particularly since Ecuador has a Pacific coastline and no examples of the genus have been recorded from eastern South America or Africa.

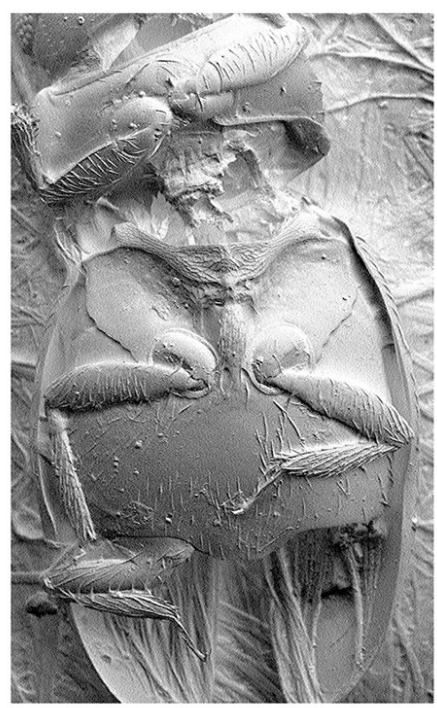

B

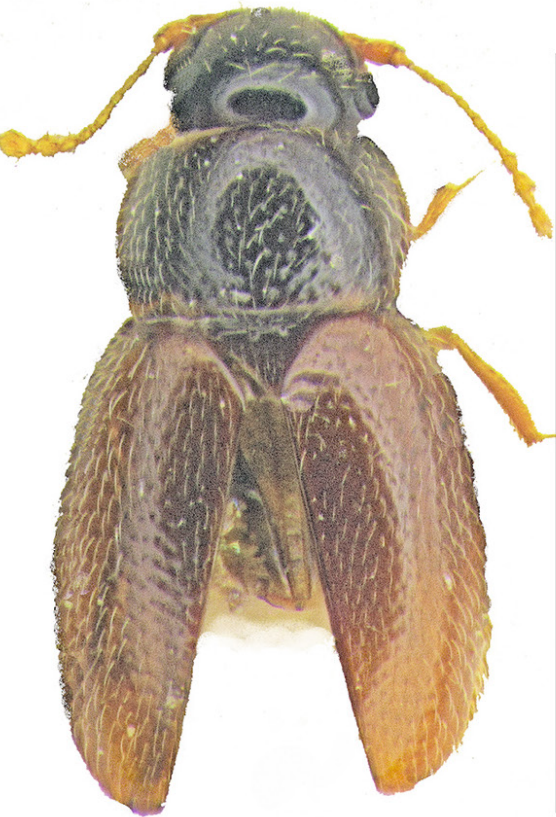

A

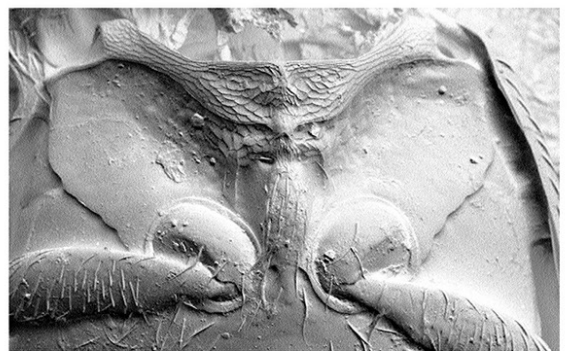

E

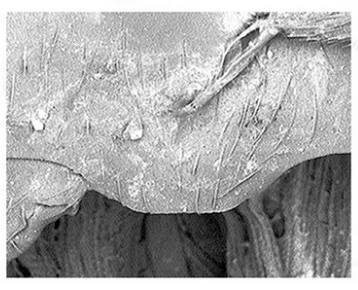

$\mathrm{F}$

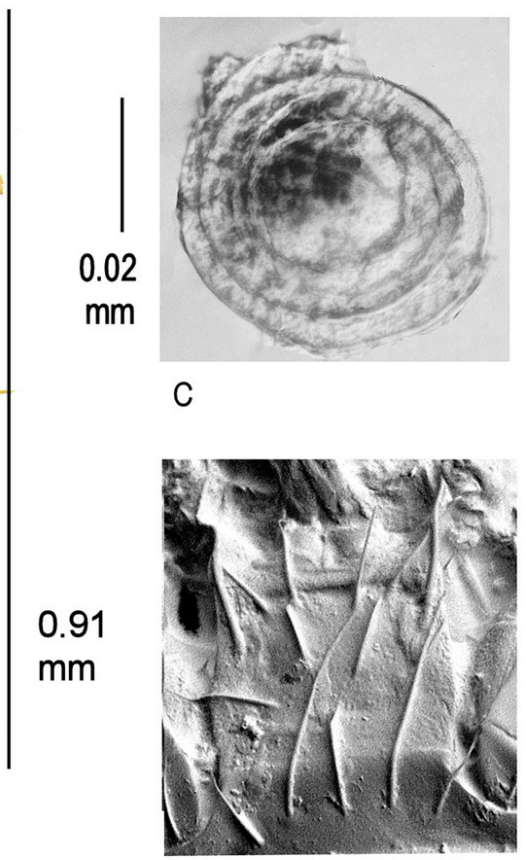

D

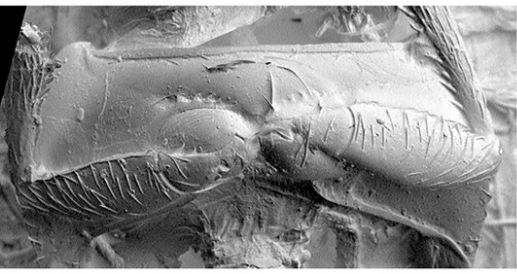

G

Fig. 5. Notoptenidium brunneum sp. nov. A. Habitus. B. Venter $\times 298$. C. Spermatheca. D. Mentum and prementum $\times 1460$. E. Mesoventrite $\times 595$. F. Posterior margin of the metaventrite between the metacoxae $\times 590$. G. Prosternum $\times 595$. 
Tribe Discheramocephalini Grebennikov, 2009

Genus Americoptilium Darby, 2018

\section{Type species}

Americoptilium convexum Darby, 2018.

\section{Remarks}

This genus was described by Darby (2018b) on the basis of a single species and specimen from Ecuador, A convexum, also collected by J. McClarin. The very narrow waist and overall form are very similar to conditions in Africoptilium Johnson 1967, described from the three species A. concinnum, A. marginatum and A. mimicum from Africa and placed in the Discheramocephalini by Grebennikov (2009), but Americoptilium differs from that genus in the small spermatheca with conventional pump, as in many other Ptiliidae, the lack of a perforated mesoventrite and the lack of lateral 'wings' on the mentum. The placement of the genus in the Discheramocephalini despite the absence of mesoventrite perforations is discussed by Darby (2018b).

Americoptilium nigrescens sp. nov. urn:lsid:zoobank.org:act:447F0DE6-7AF8-4197-ABE2-00CCCF5EC8DE

Fig. 6A-D

\section{Etymology}

Named after the dark colour of the species.

\section{Material examined}

\section{Holotype}

ECUADOR • ơ; Napo, Cosanga, Camp; 2100 a.s.1.; 30 May 2018; tray; J. McClarin leg.; QCAZM.

\section{Description}

Size. Habitus length $0.65 \mathrm{~mm}$ (Fig. 6A).

CoLour. Dark brown/black, shining, appearing polished, very finely and sparsely punctured with very short pubescence, legs and antennae yellow/brown, antennal club darker.

Head. Partially concealed by pronotum in dorsal view. Pubescence on anterior part of disc longer than on pronotum and elytra; width across eyes $0.19 \mathrm{~mm}$; antennomeres III-XI length $0.24 \mathrm{~mm}$; mentum and prementum chaetotaxy difficult to make out, sides strongly rounded to anterior margin.

Pronotum. Length $0.21 \mathrm{~mm}$, width $0.20 \mathrm{~mm}$, globular, tapering strongly to narrow waist before elytra, lateral margins finely bordered.

ELYTRA. Length $0.43 \mathrm{~mm}$, width $0.28 \mathrm{~mm}$, strongly rounded to narrow waist, widest medially, then straightening and tapering posteriorly.

ScutelLum. Narrow, elongate.

Prosternum. Wide in front of the adjacent procoxae.

Mesoventrite. Glabrous and without reticulation, form of collar unclear, without humeri; mid-keel and keel fused, widest anteriorly and tapering to point between the procoxae; procoxal anterior border wide and right angled; mesocoxae narrowly separated; meso/metaventrite suture obscured. 
Metaventrite. Length $0.17 \mathrm{~mm}$, width $0.25 \mathrm{~mm}$, sparsely pubescent, distance between metacoxae $0.03 \mathrm{~mm}$, metepisternal sutures not visible.

Male genitalia. Aedeagus (Figs 5Ba-Bb).

Female genitalia. Not known.

\section{Remarks}

Description of this species on the basis of a single specimen is considered to be justified by the rarity of this genus, only one other specimen of which, the holotype of A. convexum Darby, 2018, a female, also from Ecuador, is known. Americoptilium nigrescens sp. nov. is distinguished from that species by the less rounded and narrower body form, and the darker colour. It is possible, should the species be shown in the future to exhibit sexual dimorphism, that $A$. nigrescens sp. nov. might be confirmed as a male A. convexum, though it should be noted that in describing the three species of the closely related African genus Africoptilium, Johnson (1967) did not mention sexual dimorphism as being present, and neither did Grebennikov (2009) in his later redescription of that genus.

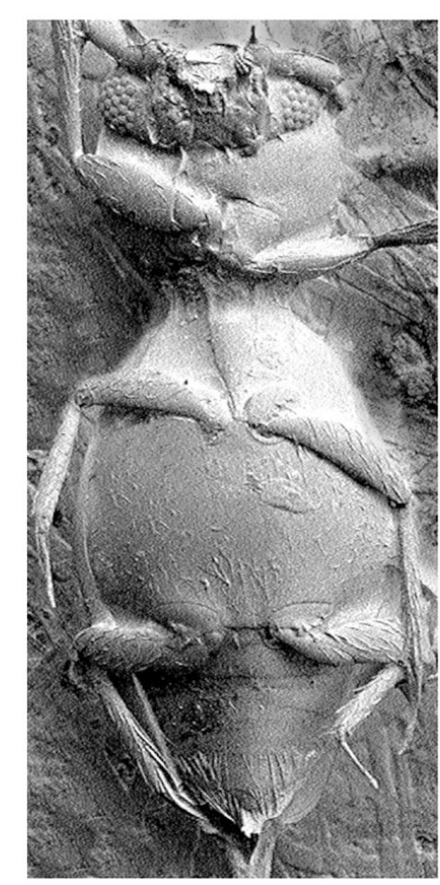

D

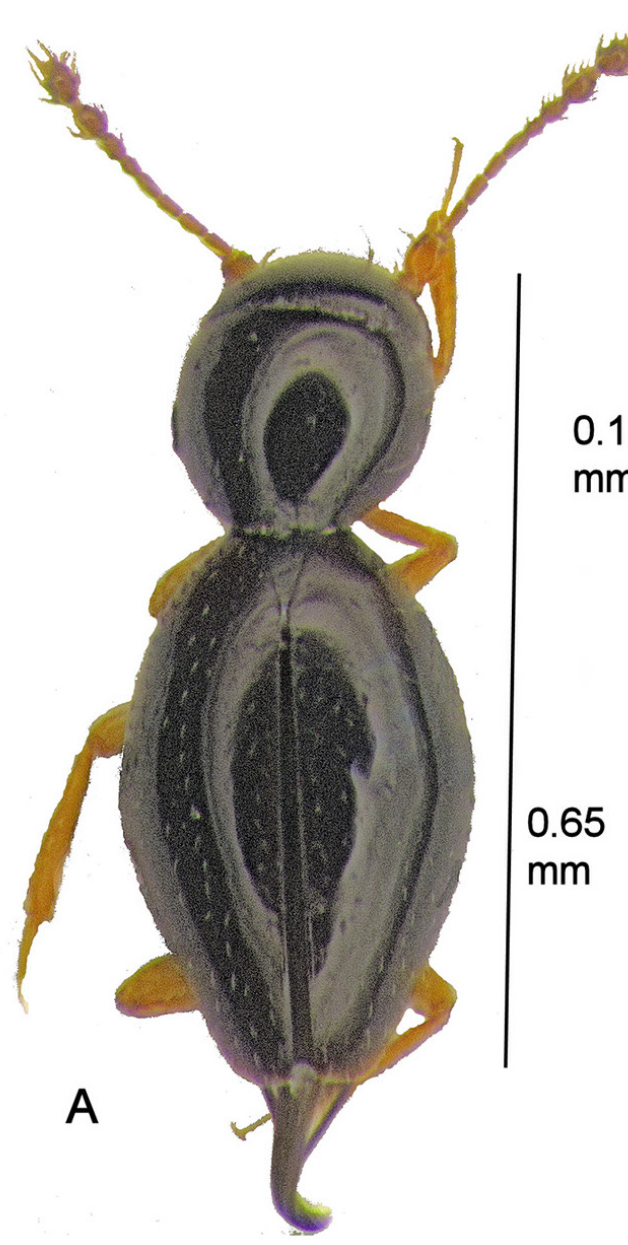

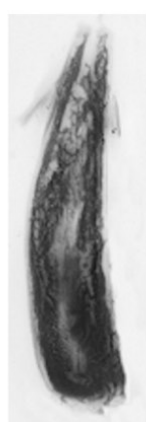

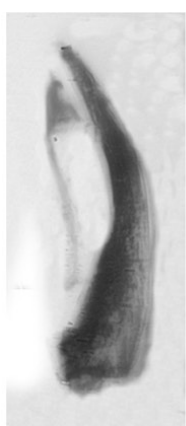

$\mathrm{Ba}$

$\mathrm{Bb}$

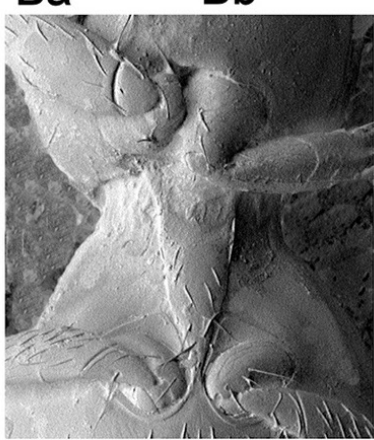

C

Fig. 6. Americoptilium nigrescens sp. nov. A. Habitus. B. Dorsal $(\mathrm{Ba})$ and lateral $(\mathrm{Bb})$ views of the aedeagus. C. Mesoventrite $\times 675$. D. Venter $\times 240$. 
Genus Discheramocephalus Johnson 2007

\section{Type species}

Discheramocephalus semisulcatus, 2007.

\section{Remarks}

Sixteen species of this distinctive genus have been described to date from Madagascar, Peru, Solomon Islands, Indonesia and Africa, and Johnson (2007) stated that he had also seen specimens from Brazil and Sri Lanka. This is the first record of the genus from Ecuador.

Discheramocephalus nigerrimus sp. nov. urn:1sid:zoobank.org:act:6D903FF0-39BB-4CA1-987E-92998C750375

Fig. 7A-D

\section{Etymology}

Named after the dark colour of this species.

\section{Material examined}

\section{Holotype}

ECUADOR • 3 ; Napo, Cosanga, Camp; 2100 m a.s.1.; 23 Mar. 2018; flight intercept trap; J. McClarin leg.; QCAZM.

\section{Description}

Size. Habitus length $0.64 \mathrm{~mm}$ (Fig. 5A).

CoLour. Dark brown/black, shining, appearing polished, glabrous, legs and antennae yellow/brown, antennal club darker.

HEAD. With distinctive sculpturing and long pubescence behind eye, including two linear depressions extending, but not joined, onto vertex (Fig. 7C) and much deeper depression behind this; width across eyes $0.19 \mathrm{~mm}$; antennomeres III-XI length $0.21 \mathrm{~mm}, \mathrm{X}-\mathrm{XI}$ forming distinct club; mentum front angles rounded, then tapering slightly to wide base, prementum wide from side to side but narrow from front to back, with four setae.

Pronotum. Length $0.16 \mathrm{~mm}$, width $0.21 \mathrm{~mm}$, sparsely pubescent, with two longitudinal linear depressions situated medially and two at sides, medial depressions widest basally and flanked by pair of much shorter foveae on each side; pronotal lateral margins strongly sinuate posteriorly, widening to posterior angles, lateral margin with two distinct setae bearing concave sinuations in front of scutellum (Fig. 7B).

ELYTRA. Length $0.42 \mathrm{~mm}$, width $0.27 \mathrm{~mm}$, sparsely pubescent, evenly rounded, widest medially, suture clearly bordered.

Scutellum. With narrow keel, broadest at base and extending to apex.

Mesoventrite. Collar broad, strongly reticulate, raised medially, tapering to base at junction with extension of metaventrite, humeri with projecting teeth, position of mesepiventral suture marked by raised line from middle of collar extension to outside of mesocoxae (Fig. 7D). 
MetaVentrite. Length $0.18 \mathrm{~mm}$ (measured to anterior tip of extension between mesocoxae), width $0.22 \mathrm{~mm}$, sparsely pubescent, with wide anterior extension between mesocoxae terminating in blunt point, lateral margins running into mesocoxal cavity borders; positions of metepisternal sutures visible as extensions of those on mesoventrite, effaced before reaching posterior margin of metaventrite (Fig. 7D).

Male genitalia. Aedeagus (Figs 7Ba-Bb).

Female genitalia. Not known.

\section{Remarks}

The description of this species based on a single specimen is justified because only one other specimen of the genus is known from the country (see next species). It is distinguished from D. striatus sp. nov. by the lack of striae on the elytra. It is only likely to be confused with D. bisulcatus Darby, 2013 among the other described species but differs from it in the narrower collar extension and the interrupted linear depression between the eyes.

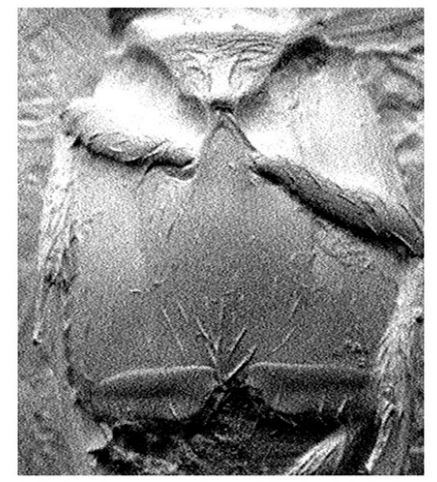

D

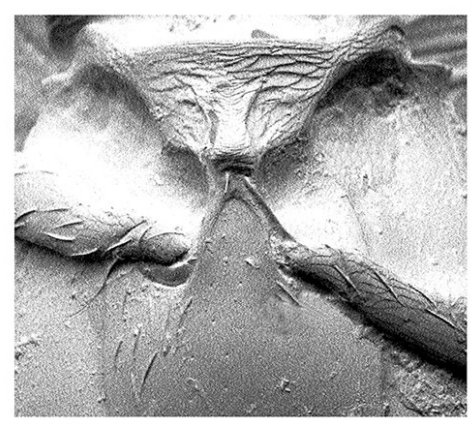

E

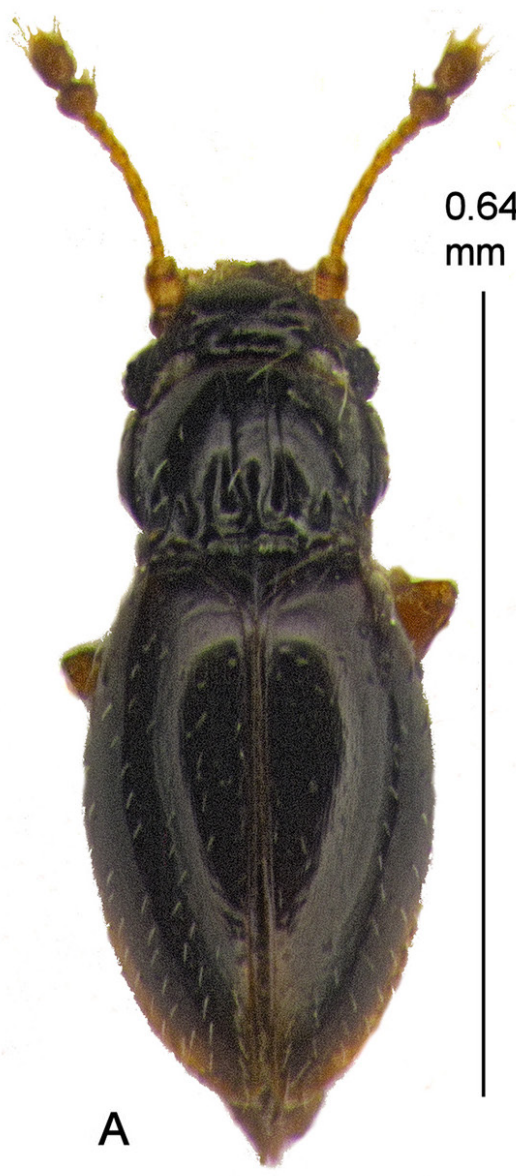

B

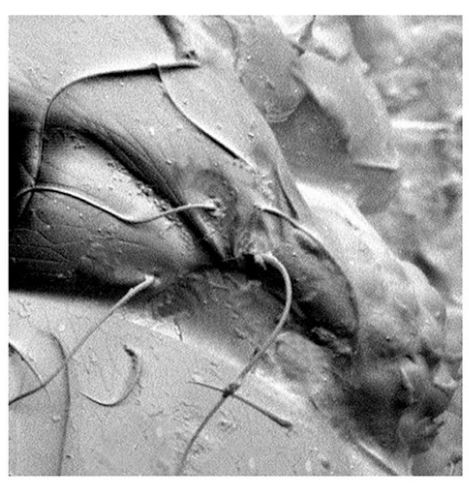

C

Fig. 7. Discheramocephalus nigerrimus sp. nov. A. Habitus. B. Pronotum $\times 725$. C. Side of head $\times 2220$. D. Meso- and metaventra $\times 830$. E. Mesoventrite keel and metaventrite projection between mesocoxae $\times 830$. 
Discheramocephalus striatus sp. nov.

urn:1sid:zoobank.org:act:37D029E3-05EF-4EA6-9305-EE17CE070185

Fig. $8 \mathrm{~A}-\mathrm{D}$

\section{Etymology}

Named after the striations on the elytra.

\section{Material examined}

\section{Holotype}

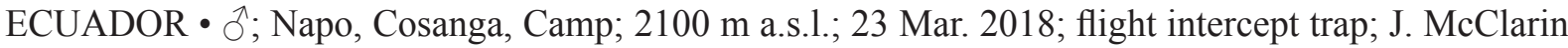
leg.; QCAZM.

\section{Description}

Size. Habitus length $0.74 \mathrm{~mm}$ (Fig. 8A).

CoLour. Dark brown/black, shining, appearing polished, glabrous, legs and antennae yellow/brown, antennal club darker.

HEAD. With distinctive sculpturing behind eye, including a single linear depression extending across vertex (Fig. 8C) and much larger and deeper depression with pair of setae behind eyes; width across eyes $0.20 \mathrm{~mm}$; antennomeres III-XI length $0.26 \mathrm{~mm}$, X-XI forming a distinct club; mentum front angles rounded, then tapering slightly to wide base, prementum wide from side to side but narrow from front to back, with four setae.

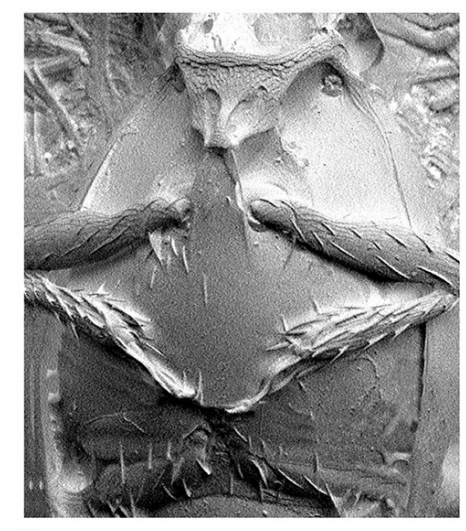

D

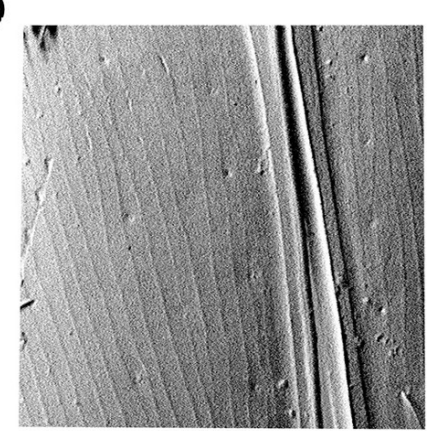

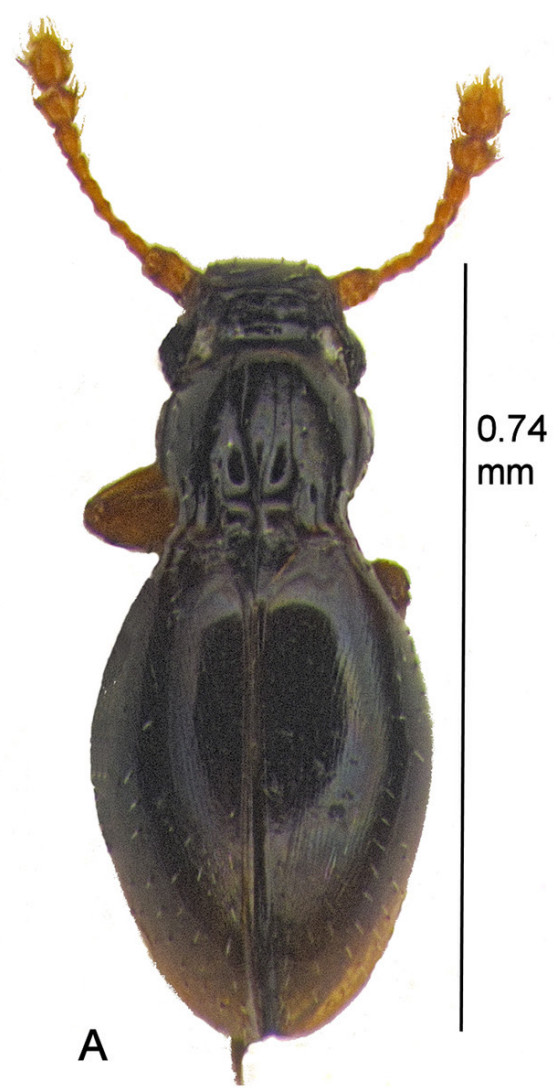

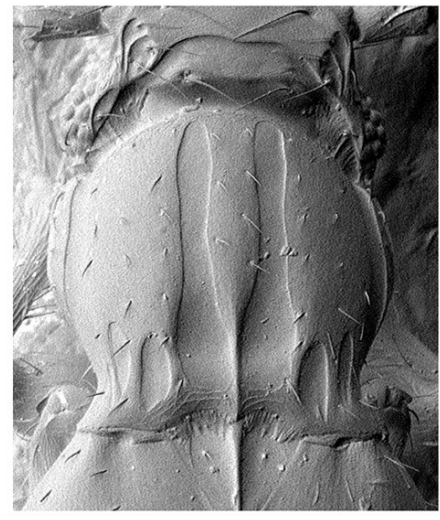

B

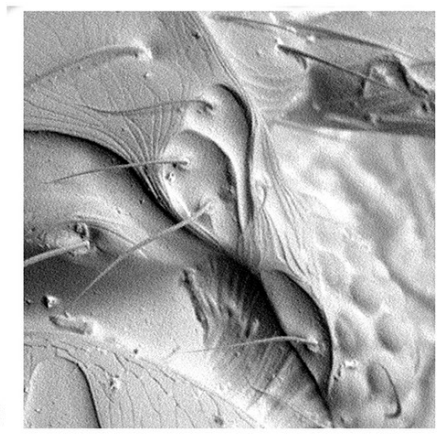

Fig. 8. Discheramocephalus striatus sp. nov. A. Habitus. B. Pronotum $\times 570$. C. Side of head $\times 1520$. D. Meso- and metaventra $\times 460$. E. Elytra showing striations and sutural margin $\times 1120$. 
Pronotum. Length $0.16 \mathrm{~mm}$, width $0.22 \mathrm{~mm}$, sparsely pubescent, with two longitudinal, linear depressions situated medially and two at sides, medial depressions widest basally and flanked by pair of much shorter foveae on each side, outermost ones slightly longer than innermost pair, pronotal lateral margins strongly sinuate posteriorly, widening to posterior angles, lateral margin with two distinct, setae-bearing concave insinuations in front of scutellum (Fig. 8B).

ELYTRA. Length $0.51 \mathrm{~mm}$, width $0.33 \mathrm{~mm}$, finely striate throughout, sparsely pubescent, evenly rounded, sutural margins strongly bordered (Fig. 8E).

Scutellum. Triangular, with narrow median keel broadest at base and extending to sharp point at apex.

Mesoventrite. Collar broad, strongly reticulate, sharply angled posteriad at anterior angles, forming two deep pits and barely extending onto humeri, which are without teeth, without mid-keel, medial, raised extension of collar joining with anterior margin of metaventrite; mesepiventral suture from middle of collar extension to outside of mesocoxae clearly marked (Fig. 8D).

Metaventrite. Length $0.19 \mathrm{~mm}$ (measured to anterior tip of extension between mesocoxae), width $0.26 \mathrm{~mm}$, sparsely pubescent, with wide anterior extension between mesocoxae terminating in blunt point, lateral margins running into mesocoxal cavity borders, marked by two long setae; positions of metepiventral sutures visible as extensions of those on mesoventrite, effaced before reaching posterior margin of metaventrite (Fig. 8D).

Male Genitalia. Aedeagus (Fig 8B).

Female genitalia. Not known.

\section{Remarks}

The description of this species based on a single specimen is justified because only one other specimen of the genus is known from the country (see preceding species). It is distinguished from D. nigerrimus sp. nov. and all other known Discheramocephalus spp. by the presence of the striae on the elytra.

\section{Discussion}

This paper brings the total number of species of Ptiliidae recorded from Ecuador to 18, all collected by Jim McClarin, mostly at one site. All are new to science and emphasise the importance of the Neotropical region for the study of this family. In 1982-83 Dr Alfred Newton and Dr Margaret Thayer made extensive collections in Chile, and more recently Dr Petr Baňař at three sites in Bolivia and Dr Caroline Chaboo and her students at two field stations in Peru (Darby 2018b). Their collections also produced many new species. Considering the huge size of the area and richness of habitats, particularly tropical rain forest, these efforts are slight. Less than two dozen species in total have been recorded from Brazil, Argentina, Colombia, Paraquay, Uruquay, Venezuela, Guyana, Suriname and French Guiana. That figure compares with the 56 species which have been recorded from the UK alone. Many expeditions must surely have made collections of Coleoptera which may include Ptiliidae in these countries but if so, they remain undetected. Future work promises to be very rewarding.

\section{Acknowledgements}

I am very grateful to the QCAZ Museum for entrusting me with this material; to Jim McClarin for his efforts in collecting, corresponding, and arranging for the museum to send the material to me; and to Cliff Keil for managing various practical matters. To Max Barclay I owe thanks for reading through the text and to Dr Alfred Newton I owe thanks for checking and correcting the names of my new species. 


\section{References}

Blackwelder R.E. 1944-1957. Checklist of the Coleopterous Insects of Mexico, Central America, the West Indies, and South America. Smithsonian Institution, Washington DC.

Darby M.D. 2016a. Studies of Peruvian Ptiliidae (Coleoptera) 3: the genus Discheramocephalus Johnson including six new species, and validation of the unavailable generic name Phytotelmatrichis Darby and Chaboo. Zootaxa 4097 (3): 416-425. https://doi.org/10.11646/zootaxa.4097.3.9

Darby M.D. 2016b. Studies of Peruvian Ptiliidae (Coleoptera) 5: Chaska nawi, a new genus and species of Acrotrichinae, Acrotrichini. Zootaxa 4161 (1): 133-136. https://doi.org/10.11646/zootaxa.4161.1.9

Darby M.D. 2016c. Studies of Peruvian Ptiliidae (Coleoptera) 4: Peruvium a new subgenus of Ptenidium with seven new species. Zootaxa 4107 (3): 392-402. https://doi.org/10.11646/zootaxa.4107.3.7

Darby M.D. 2018a. Studies of Ptiliidae (Coleoptera) in the spirit collection in the Natural History Museum London 2: New species and records from P. Hammond's visit to New Zealand in 1983-84. Entomologists's Monthly Magazine 154 (3): 179-196. https://doi.org/10.31184/M00138908.1543.3924

Darby M.D. 2018b. New records and species of Ecuadorian featherwing beetles including a new monotypic genus Americoptilium n. gen. and a new species of Phytotelmatrichis inhabiting the phytotelmata of Heliconia plants (Coleoptera, Ptiliidae). Entomologische Blätter und Coleoptera 114: $151-166$.

Darby M.D. In press. A revision of Cissidium (Coleoptera: Ptiliidae) with seventy-seven new species. European Journal of Taxonomy.

Darby M.D. \& Chaboo C.S. 2015a. Beetles (Coleoptera) of Peru: a survey of the families. Ptiliidae Heer, 1843. Journal of the Kansas Entomological Society 88 (2): 182-183.

Darby M.D. \& Chaboo C.S. 2015b. Phytotelmatrichis a new genus of Acrotrichinae (Coleoptera: Ptiliidae) associated with the phytotelmata of Zingiberales plants in Peru. Zootaxa 4052 (1): 96-106. https://doi.org/10.11646/zootaxa.4052.1.4

Grebennikov V.V. 2009. Discheramocephalini, a new pantropical tribe of featherwing beetles (Coleoptera: Ptiliidae): description of new taxa and phylogenetic analysis. Systematic Entomology 34: 113-136.

Johnson C. 1967. Studies on Ethiopian Ptiliidae I. Africoptilium gen. n. from Central Africa. The Entomologist 100: 288-292.

Johnson C. 1982a. An introduction to the Ptiliidae of New Zealand. New Zealand Journal of Zoology 9: $337-376$.

Johnson C. 1982b. Ptiliidae (Coleoptera) from the Galapagos and Cocos Islands. Bresnia 19/20: 189199.

Manuscript received: 28 June 2019

Manuscript accepted: 21 August 2019

Published on: 31 January 2020

Topic editor: Gavin Broad

Section editor: Max Barclay

Desk editor: Jeroen Venderickx 
DARBY M. Eight new species of Ptenidiini and Discheramocephalini

Printed versions of all papers are also deposited in the libraries of the institutes that are members of the EJT consortium: Muséum national d'histoire naturelle, Paris, France; Meise Botanic Garden, Belgium; Royal Museum for Central Africa, Tervuren, Belgium; Royal Belgian Institute of Natural Sciences, Brussels, Belgium; Natural History Museum of Denmark, Copenhagen, Denmark; Naturalis Biodiversity Center, Leiden, the Netherlands; Museo Nacional de Ciencias Naturales-CSIC, Madrid, Spain; Real Jardín Botánico de Madrid CSIC, Spain; Zoological Research Museum Alexander Koenig, Bonn, Germany; National Museum, Prague, Czech Republic. 